\title{
Willingness to change car use to commute to the UPTC main campus, Colombia: A hybrid discrete choice modeling approach
}

\author{
Luis Márquez \\ Universidad Pedagógica y Tecnológica de \\ Colombia \\ luis.marquez@uptc.edu.co \\ Jose J. Soto \\ Universidad Tecnológica de Bolívar \\ jsoto@utb.edu.co
}

\author{
Luis F. Macea \\ Pontificia Universidad Javeriana de Cali \\ luis.macea@javerianacali.edu.co
}

\begin{abstract}
This paper studies the willingness to change car use when commuting to a university campus. We estimated a hybrid discrete choice (HDC) model to test the hypothesis that, in addition to traditional tangible attributes, the willingness to change car use to more sustainable transportation modes also depends on the pro-environmental attitude and the perceived convenience of each transportation alternative. We found that teachers have better pro-environmental attitudes than students and administrative staff, but senior individuals and people who own an above-average priced car have negative effects on this attitude. We concluded that in addition to car ownership, the price of a car is also a decisive factor in the willingness to change car use. On-campus parking fees were identified as a key variable for reducing car use when commuting to campus and for financing more sustainable transportation modes. This paper contributes to the literature on sustainable mobility on university campuses and is the first based on an HDC modeling approach that integrates tangible attributes and latent variables into this context.
\end{abstract}

\section{Article history:}

Received: September 7, 2018

Received in revised form:

February 19, 2019

Accepted: May 1, 2019

Available online: May 14, 2019

\section{Introduction}

Much research is permanently ongoing to improve campus sustainability performance (Hancock \& Nuttman, 2014), as is evidenced in the extensive academic literature that is defining new ways to face the sustainable mobility challenges on university campuses. This is not surprising given that university campuses constitute important destinations in cities and generate a significant number of visits (Vale, Pereira \& Viana, 2018). Nowadays, many university campuses are suffering from serious mobility issues, especially those resulting from excessive private car use by students, teachers, and administrative staff.

As the mobility issues go beyond the university campuses, efforts made by universities to strengthen comprehensive mobility systems can promote a positive image to the greater society that is increasingly concerned with environmental movement (Finlay \& Massey, 2012). Accordingly, the promotion of alternative transportation modes and the limitation of car usage on campuses can lead to environmental,

Copyright 2019 Luis Márquez, Luis F. Macea, \& Jose J. Soto

http://dx.doi.org/10.5198/jtlu.2019.1460

ISSN: 1938-7849 | Licensed under the Creative Commons Attribution - Noncommercial License 4.0

The Journal of Transport and Land Use is the official journal of the World Society for Transport and Land Use (WSTLUR) and is published and sponsored by the University of Minnesota Center for Transportation Studies. 
social and economic benefits for the local and university community, which can be reflected in a better public image by decreasing the negative effects of car use (Bertolini \& le Clercq, 2003).

Sustainability is an important topic that needs to be better integrated into the economy, society, politics, culture and the overarching structure of the university (Finlay \& Massey, 2012). Motivating individual car users to shift to sustainable transport modes has been a challenge that universities have approached in different ways, depending on the context. In general, promoting and maximizing the use of sustainable transportation modes and minimizing private car use are the common objectives of the sustainable mobility plans of universities (e.g., Atherton \& Giurco, 2011).

University campuses have developed strategies to reduce greenhouse gas emissions attributed to mobile sources. Among the most common strategies are controlling illegal parking (Cruz, Barata, Ferreira, \& Freire, 2017), reducing parking spaces (Terrier, Berdier \& Bouyer, 2017), reducing or eliminating free parking (Vale et al., 2018), introducing parking charges (Cruz et al., 2017), increasing parking fees (Danaf, Abou-Zeid, \& Kaysi, 2014), promoting taxi-sharing service (Aoun, Abou-Zeid, Kaysi, \& Myntti, 2013); implementing "carrot and stick" programs in which carpooling is promoted as a good thing for curbing car use (e.g., Azzali \& Sabour, 2018), or even paying individuals who carpool to campus (Levy \& Marans, 2012). Some more specific studies have focused on determining the optimum parking price (Filipovitch \& Boamah, 2016).

A recent review of the international academic literature on sustainable mobility in university campuses indicates that this topic is a major concern for both European and American universities. Table 1 summarizes a wide range of studies from the United States, Spain and, to a lesser extent, other European countries such as France, Greece, and Portugal. A smaller number of studies detected in the academic literature come from developing and emerging countries (e.g., Brazil, Chile, and Qatar). This does not suggest that there are no studies on sustainable mobility from universities in other countries but only that they, to the best of our knowledge, have not been reported in peer-reviewed international scientific journals.

Table 1. Research on campuses' sustainable mobility

\begin{tabular}{|c|c|c|c|}
\hline Country & University campus & Focus & Reference \\
\hline Australia & $\begin{array}{l}\text { University of } \\
\text { Technology, Sydney }\end{array}$ & $\begin{array}{l}\text { Design of a campus climate change strategy, trans- } \\
\text { port strategy, and paper reduction strategy }\end{array}$ & Atherton \& Giurco, 2011 \\
\hline \multirow[t]{2}{*}{ Brazil } & $\begin{array}{l}\text { University of São Paulo, } \\
\text { campus in São Carlos }\end{array}$ & $\begin{array}{l}\text { Barriers, motivators, and strategies to promote sus- } \\
\text { tainable mobility in the university community }\end{array}$ & Stein \& Rodrigues, 2017 \\
\hline & University of Coimbra & $\begin{array}{l}\text { Strategies to ensure more rational use of available } \\
\text { parking places and to reduce greenhouse gas emis- } \\
\text { sions }\end{array}$ & Cruz et al., 2017 \\
\hline Chile & $\begin{array}{l}\text { Universidad de Talca, } \\
\text { Curico campus }\end{array}$ & Evaluation of greenhouse gas emissions & $\begin{array}{l}\text { Vásquez, Iriarte, Almeida, \& } \\
\text { Villalobos, } 2015\end{array}$ \\
\hline France & $\begin{array}{l}\text { University campus } \\
\text { Lyon Tech-la-Doua }\end{array}$ & $\begin{array}{l}\text { Proposing eco-mobility scenarios based on high- } \\
\text { lighting the links between different transportation } \\
\text { modes and their associated environmental impacts }\end{array}$ & Terrier et al., 2017 \\
\hline Greece & $\begin{array}{l}\text { Aristotle University of } \\
\text { Thessaloniki }\end{array}$ & $\begin{array}{l}\text { Alleviating the impacts of traffic congestion that un- } \\
\text { dermine mobility and accessibility conditions }\end{array}$ & $\begin{array}{l}\text { Pitsiava-Latinopoulou, Bas- } \\
\text { bas \& Gavanas, } 2013\end{array}$ \\
\hline Portugal & $\begin{array}{l}\text { University of Lisbon, a } \\
\text { multi-campus } \\
\text { university }\end{array}$ & $\begin{array}{l}\text { Relationship between the residential and workplace } \\
\text { built environments and the commuting patterns of } \\
\text { staff and students }\end{array}$ & Vale et al., 2018 \\
\hline Lebanon & $\begin{array}{l}\text { American University of } \\
\text { Beirut (AUB) }\end{array}$ & $\begin{array}{l}\text { The assessment of public policies that would en- } \\
\text { courage students to switch toward more sustainable } \\
\text { modes and their applicability to the socio-demo- } \\
\text { graphic and transport context of Beirut. }\end{array}$ & Danaf et al., 2014 \\
\hline
\end{tabular}




\begin{tabular}{|c|c|c|c|}
\hline Qatar & Qatar University & $\begin{array}{l}\text { Actions and recommendations that can support and } \\
\text { evolve the current mobility system }\end{array}$ & Azzali \& Sabour, 2018 \\
\hline \multirow[t]{4}{*}{ Spain } & University of Cantabria & $\begin{array}{l}\text { Parking and mobility policies to promote sustain- } \\
\text { ability in university campuses }\end{array}$ & $\begin{array}{l}\text { dell'Olio, Cordera, Ibeas, } \\
\text { Barreda, Alonso \& Moura, } \\
2018\end{array}$ \\
\hline & $\begin{array}{l}\text { University of the } \\
\text { Basque Country of San } \\
\text { Sebastian }\end{array}$ & $\begin{array}{l}\text { Production and implementation of a safe and sus- } \\
\text { tainable displacement plan for the different collec- } \\
\text { tives that move daily about the campuses }\end{array}$ & $\begin{array}{l}\text { Gurrutxaga, Iturrate, Oses } \\
\text { \& Garcia, } 2017\end{array}$ \\
\hline & $\begin{array}{l}\text { Autonomous } \\
\text { University of Barcelona, } \\
\text { metropolitan campus }\end{array}$ & $\begin{array}{l}\text { Influence of location, socioeconomic factors, and } \\
\text { behavior on car travel demand }\end{array}$ & $\begin{array}{l}\text { Soria-Lara, Marquet \& Mi- } \\
\text { ralles-Guash, } 2017\end{array}$ \\
\hline & University of Barcelona & $\begin{array}{l}\text { Accounting of the transport patterns, motivations, } \\
\text { barriers and user preferences }\end{array}$ & $\begin{array}{l}\text { Miralles-Guasch } \\
\text { Domene, } 2010\end{array}$ \\
\hline \multirow[t]{5}{*}{$\begin{array}{l}\text { United } \\
\text { States }\end{array}$} & $\begin{array}{l}\text { University of } \\
\text { California, Berkeley } \\
\text { campus }\end{array}$ & Flexibility of work schedule and parking preferences & $\mathrm{Ng}, 2017$ \\
\hline & $\begin{array}{l}\text { Minnesota State } \\
\text { University, Mankato } \\
\text { campus }\end{array}$ & Achieving optimum parking efficiency on campus & $\begin{array}{l}\text { Filipovitch \& Boamah, } \\
2016\end{array}$ \\
\hline & Kent State University & $\begin{array}{l}\text { Analyzing some the opportunities and impediments } \\
\text { in increasing walking and bicycling }\end{array}$ & Kaplan, 2015 \\
\hline & $\begin{array}{l}\text { University of } \\
\text { California, Berkeley } \\
\text { ampus }\end{array}$ & $\begin{array}{l}\text { How parking price reforms, traveler information } \\
\text { systems, and incentives affect an increase in the use } \\
\text { of public transit and non-motorized modes }\end{array}$ & Riggs, 2014 \\
\hline & University of Kansas & $\begin{array}{l}\text { Exploring the possibilities of teaching environmen- } \\
\text { tal planning by focusing on campus sustainability }\end{array}$ & White, 2003 \\
\hline
\end{tabular}

Against this background, it may not always be obvious why universities persist in subsidizing parking by providing it at no charge, which is decisive for car commuters and especially for students (Vale et al., 2018), or at prices that do not fully take into account parking costs (Barata, Cruz, \& Ferreira, 2011). Many Colombian universities maintain free curb parking, instead of encouraging a modal shift away from private car use to other transportation modes. This leads to the mismanagement of scarce campus land, with widespread ramifications for safety, land resources, health, and the environment.

An introductory check of peer-reviewed international scientific journals showed that campus sustainability strategies differ across geographical spaces, including the specific features of each campus in relation to the urban transportation system, and the commuting characteristics of teachers, administrative staff, and students (e.g., Pitsiava-Latinopoulou et al.,2013). This means that the analysis of sustainable mobility on university campuses across latitudes is necessary, particularly in developing countries where there is scarce academic literature on the matter, as evidenced in the summary previously presented in Table 1.

On the other hand, students represent a significant percentage of the regions' traveling population (Khattak, Wang, Son, \& Agnello, 2011). In this sense, it is essential to analyze their urban travel behavior characteristics in order to formulate appropriate public policies that can help institutions promote sustainable urban mobility plans and to implement new sustainable transportation modes. Although many studies have addressed the role of attitudes in travel behavior change, such attitudes are a cultural factor in the decision-making process that depend of the structure of the local physical environment (Cattaneo, Malighetti, Moriotti, \& Paleari, 2018), the socio-demographic and transport context (Danaf et al., 2014) as well as the influence of the social marketing (Hook, 2007), which should not be overlooked.

Within this general framework, the present paper is indeed the first to present results from a Colombian context in which pro-environmental attitude and the perceived convenience of each trans- 
portation alternative are analyzed in order to test the people's willingness to change car use to more sustainable transportation modes. It is also an important contribution to the literature on sustainable mobility on university campuses by being the first based on a hybrid discrete choice (HDC) modeling approach that integrates tangible attributes and latent variables. It is based on data that were collected by stated preference surveys that were conducted at the Universidad Pedagógica y Tecnológica de Colombia (UPTC), which is one of the most important public universities in the country. Specifically, our work is oriented to study the willingness to change car use when commuting to the UPTC main campus.

\section{The UPTC main campus mobility}

The UPTC is one of the most important public universities in Colombia with approximately 28,000 students on all its campuses. The UPTC main campus is located $130 \mathrm{~km}$ northeast of Bogota in the city of Tunja, which has approximately 200,000 residents. The UPTC main campus is made up of 58 buildings in an approximately 95,000-square-meter area, which includes administrative offices, classrooms, laboratories, clinics, restaurants, cafeterias, workshops, gyms, and a library. With 16,289 students, 939 teachers, and 869 administrative staff members, the UPTC main campus is the largest university campus in Tunja.

On the UPTC main campus, females represent $56 \%$ of students, $36 \%$ of teachers, and $62 \%$ of the administrative staff. However, the ownership (and use) of automobiles on campus exhibits a male gender predominance. According to the official records of the UPTC main campus generated as of the closing of March 2018, there were approximately 1400 registered car users with the following participation rates for the male gender: $80 \%$ of male students, $75 \%$ of male teachers, and $55 \%$ of male administrative staff members, which is the group with the most equal gender distribution.

The modal split of trips attracted by the UPTC main campus, which represents a little more than $10 \%$ of the Tunja trips, is similar to that of the city. Table 2 shows that, in both the UPTC main campus and Tunja, walking and buses are the main transportation modes. Because of the small bicycle infrastructural development in the city, cycling as a means of transportation is not very significant, and, possibly due to their high costs, taxis are not very important either. Although cars market share is less than public transportation and walking in both contexts, it generates a high demand for parking spaces, as usual (Manville $\&$ Shoup, 2005).

Table 2. Modal split of Tunja vis-à-vis the UPTC main campus (\%)

\begin{tabular}{lcc}
\hline Mode & City & UPTC main campus \\
\hline Walking & 44 & 48 \\
Cycling & 1 & 2 \\
Bus & 38 & 40 \\
Taxi & 4 & 2 \\
Car & 13 & 8 \\
\hline
\end{tabular}

At present, parking spaces on campus are insufficient in meeting demand. The administration of the university, such as the municipal administration, is very concerned about such a situation. For that reason, despite that it has been demonstrated to be a misguided urban transport strategy (Cantillo $\&$ Ortúzar, 2014.), in the city, a driving restriction policy according to license plate numbers has been applied with the aim to reduce the demand for parking spaces, congestion and other externalities associated with car use. The UPTC main campus has also adopted this measure since the year 2018. With this policy, the number of cars has decreased by one-fifth on each working day. This measure has moti- 
vated the university community to use other modes of transportation on restricted days. Table 3 shows the alternative transportation modes used by the university community when car access is restricted by license plate numbers.

Buses are one of the alternative transportation modes that users prefer on car restriction days, which is natural given that more than $70 \%$ of all public transportation lines in the city stop in front of the UPTC main campus, with step intervals less than 5 minutes. Because of the importance of the campus in the city, the work schedule of the university and the schedule of the provision of the public transportation service coincide, which makes the bus one of the main alternatives to commute the campus. Some car users choose to carpool and some others, depending on their trip's distance, decide to walk. A smaller proportion of car users, mainly administrative staff, opt to travel by taxi and even some decide to not shift their mode and park their cars off campus.

Table 3. Transportation mode used when car access is restricted in campus (\%)

\begin{tabular}{lcccc}
\hline Alternative transportation mode & Students & Teachers & Administrative staff & Total \\
\hline Walking & 29.7 & 16.9 & 11.7 & 19.5 \\
Bus & 46.9 & 39.4 & 41.7 & 42.6 \\
Carpooling & 6.3 & 32.4 & 23.3 & 21.0 \\
Taxi & 10.8 & 9.9 & 15.0 & 11.8 \\
Parking off campus & 6.3 & 1.4 & 8.3 & 5.1 \\
\hline
\end{tabular}

The fact that administrative staff would be less willing to change car use, as is apparent from the largest proportion of parking off campus on days with license plate number restrictions, can be related to the lower flexibility of their work schedule in comparison with students and teachers. This view is also underlined by the findings of $\mathrm{Ng}$ (2017) who stated that work schedule flexibility is a key factor that influences parking preferences, especially when there are alternative parking locations.

Although prohibiting the circulation of a proportion of cars based on their license plate numbers is clearly a measure aimed to reduce car use, it has been demonstrated that this measure does not work as expected. In the medium and long terms, some citizens, especially those with greater purchasing power, could decide to buy new and used cars, thus increasing the city's car stock (Cantillo \& Ortúzar, 2014). That is why we look forward to studying the willingness to change car use on the UPTC main campus within a framework in which restricting the use of cars by license plate numbers is not present.

\section{$3 \quad$ Methods and data}

Our behavioral hypothesis is that, in addition to traditional tangible attributes such as waiting times, travel times, urban transportation fares and on-campus parking fees, the willingness to change car use also depends on individual attitudes and perceptions of the alternatives. Consequently, we hypothesized that the intention to change private car use to more sustainable transportation modes depends not only on the above-mentioned tangible attributes but also on the pro-environmental attitude and the perceived convenience of each transportation alternative.

\subsection{Sample}

To test our hypothesis, we conducted a survey during March 2018, using a face-to-face questionnaire, to obtain a significant and representative sample of all community members of the UPTC main campus. After data cleaning, the remaining sample size was 195 individuals, which represents $14 \%$ of the 
registered car users on the UPTC main campus. The questionnaire consisted of three parts that were relevant to our study. First, the individuals faced a choice experiment and then scored the indicators of latent variables. At the end of the survey, individuals reported their main socioeconomic characteristics. The respondents were randomly selected. They were performed face-to-face since the scientific literature indicate that this sampling method delivers better results in terms of representativeness (Szolnoki \& Hoffmann, 2013). Additionally, this method provides advantages over other data collection methods (e.g., telephone survey, online surveys) in terms of accurate screening and keep focus. Both conditions highest required in stated preference methods since respondents require trading off one choice situation against another based on a set of alternatives that are pre-specified in terms of levels of different attributes. Table 4 gives an overview of the sample frequencies regarding the main socioeconomic characteristics of car users.

Table 4. Socioeconomic characteristics of the sample

\begin{tabular}{|c|c|c|c|c|c|c|c|c|}
\hline & \multicolumn{2}{|c|}{ Students } & \multicolumn{2}{|c|}{ Teachers } & \multicolumn{2}{|c|}{ Administrative staff } & \multicolumn{2}{|c|}{ Total } \\
\hline & $\mathrm{n}$ & Percent & $\mathrm{n}$ & Percent & $\mathrm{N}$ & Percent & $\mathrm{N}$ & Percent \\
\hline \multicolumn{9}{|l|}{$\begin{array}{l}\text { Socioeconomic } \\
\text { characteristic }\end{array}$} \\
\hline \multicolumn{9}{|l|}{ Gender } \\
\hline Female & 12 & 18.8 & 17 & 23.9 & 27 & 45.0 & 56 & 28.7 \\
\hline Male & 52 & 81.2 & 54 & 76.1 & 33 & 55.0 & 139 & 71.3 \\
\hline \multicolumn{9}{|l|}{ Age } \\
\hline Under 25 years & 30 & 46.9 & 0 & 0.0 & 5 & 8.3 & 35 & 17.9 \\
\hline 25 to 34 & 29 & 45.3 & 21 & 29.6 & 7 & 11.7 & 57 & 29.2 \\
\hline 35 to 44 & 4 & 6.3 & 34 & 47.9 & 37 & 61.7 & 75 & 38.5 \\
\hline 45 to 54 & 1 & 1.5 & 15 & 22.1 & 10 & 16.7 & 26 & 13.3 \\
\hline 55 or more & 0 & 0 & 1 & 0.4 & 1 & 1.6 & 2 & 1.1 \\
\hline \multicolumn{9}{|l|}{ Income level } \\
\hline Low & 4 & 6.2 & 4 & 5.6 & 3 & 5.0 & 11 & 5.6 \\
\hline Medium & 38 & 59.4 & 30 & 42.3 & 14 & 23.3 & 82 & 42.1 \\
\hline High & 22 & 34.4 & 37 & 52.1 & 43 & 71.7 & 102 & 52.3 \\
\hline
\end{tabular}

In the sample, seniority, which is the number of years that individuals have remained at the university, was, on average, 5.0 years for students, 8.2 years for teachers and 8.5 years for administrative staff. All individuals reported that the price of their car was, on average, 20 million Colombian pesos (\$USD 6900) for students, 34 million COP (\$USD 11,700) for teachers and 30 million COP (\$USD 10,300) for administrative staff. At this point, we consider it convenient to clarify that, according to the exchange rate at the time of the study, one American dollar was equivalent to 2900 COP.

\subsection{Discrete choice experiment}

At the beginning of the survey, individuals were faced with a stated preference experiment in a choice context in which drivers who do not share their car will be charged. According to our literature review, charging for on-campus parking appears to be a key policy that could change the travel patterns of car users and increase the utility of using alternative transportation modes (dell'Olio et al., 2018). Furthermore, the strategy of proposing changes in parking pricing has been used successfully in stated preference surveys to assess the participants' responsiveness to shifting transportation towards sustainable modes (e.g., Riggs, 2014). 
Currently, the UPTC main campus subsidizes parking by providing it at no charge. But, as mentioned above, the University has a license plate restriction policy, which is aimed to reduce car use in the campus and to encourage modal shift. The idea behind the experiment was to estimate the main variables explaining the willingness to change car use on the UPTC main campus. The choice set consisted of four alternatives aimed to curb car use, namely the following: charging for on-campus parking, carpooling, taxis, and buses. Although this is not a strictly coercive scenario, it is in line with those proposed by Terrier et al. (2017).

Despite some mobility management plans defined for university campuses have included bicycle promotion (e.g., Gurrutxaga, Iturrate, Oses, \& Garcia, 2017), according to the results of the focus groups in our study context, intentions to cycling for commuting were not significant. For this reason, we decided to remove bicycles from the set of sustainable transport alternatives that we had initially considered. Based on the distributions shown in Table 3, we added walking as another sustainable alternative for commuting to the UPTC main campus. However, after a pilot test, we also removed this alternative from our choice set since most of the users did not choose it.

Based on a pre-questionnaire among some focus groups where we asked individuals to state the most influencing factors for the alternatives, we selected the attributes of waiting times, travel times, on-campus parking fees and urban transportation fares to be part of the choice experiment. According to the expectations that users declared in the focus groups and after the proper changes we made to the pilot test, we decided to use the levels shown in Table 5.

Table 5. Attributes and levels of the experimental design

\begin{tabular}{|c|c|c|c|c|}
\hline & Charging for on-campus parking & Carpooling & Taxi & Bus \\
\hline \multicolumn{5}{|l|}{ Attribute } \\
\hline \multirow[t]{3}{*}{ Waiting time (min) } & 0 & 0 & 0 & 0 \\
\hline & 0 & 0 & 5 & 5 \\
\hline & 0 & 0 & 10 & 10 \\
\hline \multirow[t]{3}{*}{ Travel time (min) } & 15 & 25 & 15 & 20 \\
\hline & 20 & 30 & 20 & 25 \\
\hline & 25 & 35 & 25 & 30 \\
\hline \multirow[t]{3}{*}{ On-campus parking fee (COP) } & 1500 & & & \\
\hline & 2500 & & & \\
\hline & 3500 & & & \\
\hline \multirow[t]{3}{*}{ Urban transportation fare (COP) } & & & 4500 & 1500 \\
\hline & & & 5500 & 1700 \\
\hline & & & 6500 & 1900 \\
\hline
\end{tabular}

We obtained an orthogonal factorial design that was composed of 27 treatments by using Ngene (ChoiceMetrics, 2012) software. The number of treatments was too large to give all these choice situations to a single respondent, therefore, we also assigned three blocks using a minsum search that minimizes the total correlation values between the blocking column and all of the attributes. For each individual, the stated preference experiment consisted of nine choice situations and thus yielded 1755 choice responses. The experimental design maintained the attribute levels in balance instead of just having data points at only one or a few of the attribute levels. This ensures that the parameters could be well estimated over the whole range of levels. 


\subsection{Latent variables and indicators}

In the second part of our survey, individuals rated a set of effect indicators, which are hypothesized to be manifestations of the underlying latent behavioral constructs. Although latent variables cannot be measured directly, their effects on indicators are observable and can be collected through the survey (Bollen, 2002). A priori latent variables were defined by authors and tested according to focus groups and previous interviews. In this process, perceived convenience and pro-environmental attitude of each transportation alternative were identified as the main latent variables. Perceived convenience was a perceptual latent variable. It was related to the mode and its quality of being safe, reliable and comfortable. Those indicators were asked for each mode in the experimental design. The pro-environmental attitude was an attitudinal latent variable that was tied to the environmental concern when purchasing or driving a car, along with the sense of responsibility in environmental care.

In order to allow for their identification, we used the effect indicators shown in Table 6 . The expected signs for each indicator are based on the beliefs that we have about the direction in which each latent variable is going to manifest in the measurement model. As seen in Table 6, we used three indicators per latent variable. In addition, we used a 5-point Likert scale that is in line with the most frequent practice in the field of transportation choice analysis based on the HDC modeling approach (Márquez, Cantillo \& Arellana, 2018).

Table 6. Indicators of latent variables

\begin{tabular}{lc}
\hline Stem statement & Expected sign \\
\hline Pro-environmental attitude & - \\
\hline Care for the environment is the responsibility of others & + \\
When I purchased my car, I kept environmental considerations in mind & + \\
I try to drive economically to pollute less & \\
\hline Perceived convenience & + \\
\hline When I commute to the university by this alternative... & + \\
I am exposed to thefts & + \\
The estimated travel time is reliable & \\
I can carry my belongings comfortably &
\end{tabular}

\subsection{Modeling approach}

The incorporation of attitudes into the parking analysis has been successfully carried out by using the HDC modeling approach. In the Colombian context, the work of Soto, Márquez \& Macea (2018) demonstrated that, in addition to the more common tangible attributes such as parking fees, search times and access times, attitudes are also determinants for parking choices. As our context is based on the choice of transportation alternatives for commuting to the UPTC main campus, apart from the proenvironmental attitude, the perceived convenience of each alternative was added into the latent variables set. Figure 1 shows the final structure of the selected model. However, several specifications were also tested considering additional socioeconomic variables.

The HDC modeling framework postulates that users choose the alternative that maximizes their perceived utility in the same way as with the random utility theory framework. Unlike traditionally used discrete choice models, our HDC model is composed of two sub-models, a discrete choice submodel, and a latent variable sub-model. The perceived convenience and pro-environmental attitude of each transportation alternative were incorporated through structural equations (Ashok, Dillon \& Yuan, 2002) in both models. 
Except for the measurement equations that we specified as ordered logit models to capture the nature of the data (Márquez, Cantillo \& Arellana, 2018), we specified the structural and choice models as linear based on our assumptions about how the variables enter these models. We arranged the variables used in modeling into three groups: socioeconomic characteristics, latent variables, and experimental design attributes. All socioeconomic characteristics entered the latent variable sub-model as dummy variables, the experimental design attributes entered the discrete choice sub-model as continuous variables, as well as the latent variables whose variances were normalized to one. We changed the scale of the urban transportation fares and on-campus parking fees by dividing their original values by one thousand Colombian pesos.

We generate two additional variables to incorporate in the modeling. In the first place, by taking the average of each specific group as a cut point, we divided the sample into two groups. This generates the dummy variable "People with more seniority" that takes the value of one for individuals who exceed the average seniority of their group, which is 5.0 years for students, 8.2 years for teachers and 8.5 years for administrative staff. Analogously, we generated the dummy variable "Above average car price", which takes the value of one for people who own cars whose price is higher than the average of their group, which is 20 million COP for students, 34 million COP for teachers and 30 million COP for administrative staff.

We performed the maximum simulated likelihood to estimate the unknown parameters of the HDC model. The model was estimated using all the information simultaneously, which prevented the overestimation of the weights of the latent variables. We carried out all the work on a computer using OxMetrics $^{\mathrm{TM}}$ (Doornik, 2015), which is a family of software packages providing an integrated solution for the econometric analysis that has been successfully used in previous studies (Márquez, Cantillo \& Arellana, 2018; Soto et al., 2018). 


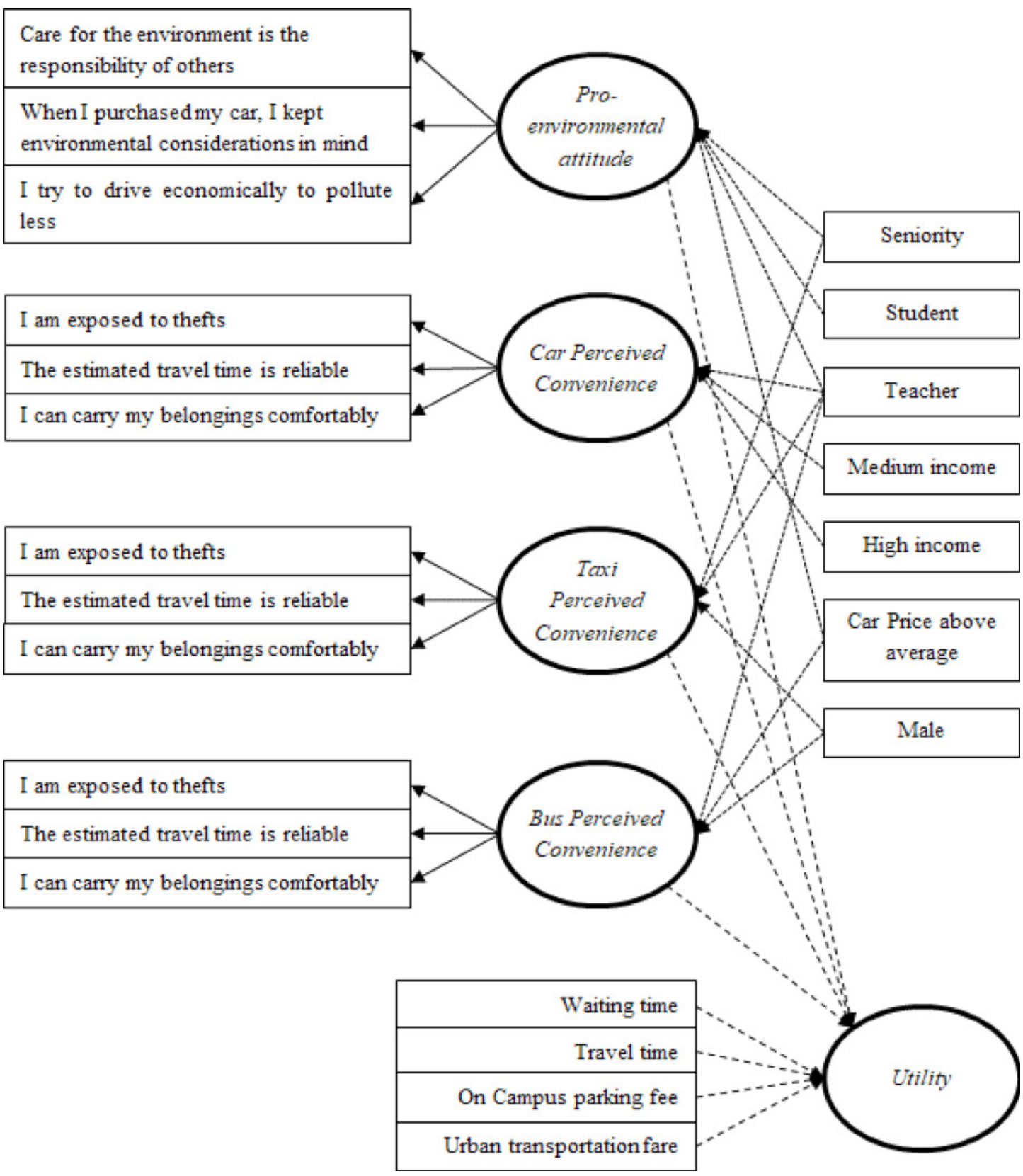

Figure 1. Full path diagram for HDC Model

In order to empirically deal with the identifiability issues of our model, we verified that the estimated parameters were not outside the range of reasonable values. Additionally, the model was estimated multiple times, and different starting values were employed for the parameters for each estimation run. We verified that in all cases we reached the same solution, thus ensuring that the obtained solution was a global maximum. 


\section{$4 \quad$ Modeling results and discussion}

The estimated models are in Table 7, which exhibits the coefficients and robust t-values for the latent variable sub-model and the discrete choice sub-model, which additionally considered the panel effect produced by having nine different choices per respondent. To simulate the likelihood, we used 500 drawings for each individual obtained from a modified Latin Hypercube sampling.

Table 7. Hybrid discrete choice model estimates

\begin{tabular}{|c|c|c|}
\hline & \multirow{2}{*}{\multicolumn{2}{|c|}{ Robust t-value }} \\
\hline & & \\
\hline \multicolumn{3}{|l|}{ STRUCTURAL SUB-MODEL } \\
\hline \multicolumn{3}{|l|}{ Pro-environmental attitude } \\
\hline Teacher & 0.733 & 3.07 \\
\hline Student & 0.496 & 1.96 \\
\hline People with more seniority & -0.439 & -2.70 \\
\hline Car price above average & -0.285 & -1.64 \\
\hline \multicolumn{3}{|l|}{ Car perceived convenience } \\
\hline Medium income & 0.387 & 1.97 \\
\hline High income & 0.667 & 1.92 \\
\hline Teacher & 0.465 & 2.05 \\
\hline \multicolumn{3}{|l|}{ Taxi perceived convenience } \\
\hline Male & 0.403 & 2.03 \\
\hline Teacher & -0.365 & -1.98 \\
\hline People with more seniority & -0.319 & -1.73 \\
\hline \multicolumn{3}{|l|}{ Bus perceived convenience } \\
\hline Male & 0.276 & 2.01 \\
\hline Teacher & -0.436 & -2.40 \\
\hline Car price above average & -0.274 & -1.83 \\
\hline \multicolumn{3}{|l|}{ MEASUREMENT EQUATIONS } \\
\hline \multicolumn{3}{|l|}{ Pro-environmental attitude } \\
\hline Care for the environment is the responsibility of others & -0.551 & -3.37 \\
\hline When I purchased my car, I kept environmental considerations in mind & 0.495 & 2.43 \\
\hline I try to drive economically to pollute less & 3.238 & 3.87 \\
\hline \multicolumn{3}{|l|}{ Perceived convenience } \\
\hline I am exposed to thefts & -2.426 & -2.81 \\
\hline The estimated travel time is reliable & 0.241 & 2.01 \\
\hline I can carry my belongings comfortably & 1.070 & 4.27 \\
\hline \multicolumn{3}{|l|}{ DISCRETE CHOICE SUB-MODEL } \\
\hline \multicolumn{3}{|l|}{ Specific alternative constants } \\
\hline Charging for on-campus parking [1] & 2.684 & 7.13 \\
\hline Carpooling [2] & 0.000 & Fixed \\
\hline Taxi [3] & -1.666 & -1.96 \\
\hline Bus [4] & -0.551 & -1.44 \\
\hline \multicolumn{3}{|l|}{ Tangible attributes } \\
\hline Waiting time $[3,4]$ & -0.167 & -8.47 \\
\hline Travel time $[1,2,3,4]$ & -0.180 & -13.02 \\
\hline
\end{tabular}




\begin{tabular}{lcr} 
On-campus parking fee [1] & -2.206 & -14.63 \\
Urban transportation fare [3, 4] & -0.167 & -8.47 \\
\hline Latent variables & & \\
\hline Pro-environmental attitude [2] & 1.107 & 5.15 \\
Perceived convenience [1, 3, 4] & 0.852 & 3.18 \\
\hline Log-likelihood & -4135.17 & \\
Log-likelihood for choice component & -1606.41 & \\
\hline
\end{tabular}

Discrete choice modeling results show that sample size was sufficient to achieve desirable asymptotic t-ratio values, i.e., to obtain asymptotically statistically significant parameter estimates (Bliemer \& Rose, 2009a, 2009b). This is fairly easy to explain since, for each individual, the stated preference experiment consisted of nine choice situations and thus yielded 1755 observations to estimate the discrete choice model. For the structural models, which were estimated with 195 observations, all the parameter estimates were statistically significant at least for a $90 \%$ confidence level. Rather than taking a large sample, our concern was to take a quality sample. However, it is possible that statistically significance of parameter estimates for the structural models could be improved with a slightly larger sample.

\subsection{Latent variable sub-model}

The structural model showed that teachers have stronger pro-environmental attitudes than students and administrative staff, while senior individuals and people who own a car with an above average price have weaker pro-environmental attitudes than others. In the choice model, we can observe that proenvironmental attitudes significantly influence carpoolers choice, as stronger attitudes increase utility and likelihood to change car use.

These findings are in line with those of Dogterom, Bao, Xu, and Ettema (2018) who found that higher education has a positive effect on the willingness to change, whereas higher income has a negative effect. It is clear to us that there may be a correlation between higher education and being a teacher, as well as between a higher income and owning a car with an above average price. Despite the fact that teachers have better pro-environmental attitudes than other members of the university community, a car's perceived convenience is also greater for them compared to others, which could negatively affect teachers' intentions to change private car use to more sustainable transportation modes.

One of the major advantages of our modeling approach is that through socioeconomic characteristics entering structural equations, we can capture the heterogeneity of the population. In this regard, we found that owning an above average priced car negatively affects bus pro-environmental attitude and perceived convenience. A similar result found by Stein and Rodrigues (2017) identified owning a car as the main obstacle to adopting sustainable modes. On the basis of our modeling results, we argue that apart from owning a car, the price is also a decisive factor for willingness to change car use.

Previous research in the context of metropolitan university campuses has shown that socioeconomic factors related to the characteristics of a university population affect travel demand by car (Soria-Lara et al., 2017). In our case, given that the structural model allowed us to capture the population's heterogeneity, we can assert that teachers and members of the university community with medium and high incomes perceive a greater utility for cars in comparison with the others and consequently they will be more motivated to use cars to commute to the campus. Compared to other members of the university community, teachers, people with more seniority and people who own a car with an above average price have lower perceptions of the convenience of using a taxi or bus. Conversely, males would be more willing to use taxis and buses to commute to the campus than would females, which is consistent with the knowledge that we have of the city's transportation system. 


\subsection{Discrete choice sub-model}

Table 7 also shows the estimates for the discrete choice sub-model. Beside the name of each variable, in curly brackets, is the number of the utility function in which we specified the corresponding variable. They are as follows: [1] Charging for on-campus parking, [2] Carpooling, [3] Taxi, and [4] Bus. Due to identification issues, Carpooling's specific constant was set to zero. All estimated parameters have the expected signs. Waiting times, travel times, on-campus parking fees, and urban transportation fares are in the expected directions. It is obvious that additional times or fares that are more expensive, reduce the utility of the alternatives. Furthermore, the signs of the latent variables indicate that these variables positively affect the utility.

Regarding tangible variables, our findings are in line with the modeling results of dell'Olio et al. (2018) who demonstrated that on-campus parking fees are a key variable for reducing the use of cars for commuting to the campus. In our case, the estimates show that car users are very sensitive to changes in on-campus parking fees, far more than they are to changes in urban transportation fares. A policy aimed at charging on-campus parking for users who do not share their cars could motivate carpooling and the use of other transportation alternatives, such as taxis and buses, hence reducing the demand for parking spaces.

On the other hand, the intention to use bicycles to commute to the UPTC main campus was not significant and, consequently, we do not include bicycles in the set of sustainable transport alternatives in our experiment. This is in line with the findings of Miralles-Guasch and Domene (2010) in the sense that one of the main limitations for changing car use to a non-motorized mode is the marginal roles of walking and cycling as means of transportation. Other studies have argued, as in our case, that the existing infrastructure discourages sustainable transportation activities (especially bicycle access) around campus (Kaplan, 2015).

However, this does not mean that bicycles are not an important alternative in search of sustainable mobility. Some studies have shown that the students living near campus should shift from cars to bicycles in order to reduce the institution's emissions (Vásquez et al., 2015). However, we feel that it is also the responsibility of teachers and administrative staff to shift from cars to more sustainable transportation modes. We are fully convinced that campuses and cities in developing countries need better cycling infrastructure to effectively promote the use of this mode.

Finally, we agree with Finlay and Massey (2012) on the fact that universities are major places to build social cultures and should not be underestimated as the perfect grounds to educate and motivate sustainable mobility. In this vein, as White (2003) discusses, using teaching spaces to explore the possibilities for campus sustainability can serve as underpinning efforts for more environmentally oriented campus plans. The analysis of prior research suggests that the UPTC main campus should pursue three types of activities to support the development of pro-environmental behaviors: education, engagement, and assessment (Levy \& Marans, 2012).

\subsection{Policy analysis}

The estimated model allowed us to forecast the market shares of each of the fourth modes taking into consideration changes on-campus parking fee, which is the easiest policy to implement and manage from the UPTC campus. In this regard, sample enumeration was used as the aggregation method (Ortúzar \& Willumsen, 2011). The market shares of each mode for each individual in the sample was estimated first and then the average was estimated. Figure 2 presents changes in market share resulting from applying the HDC model with the estimated parameters. 
As shown in Figure 2, for students (a), teachers (b) and administrative staff (c), imposing higher parking fees can cause a significant decrease in car market share. These results also show that an increase in the price of parking induces each person to share their car as a second transportation option in order to reduce their travel costs, followed by the bus and taxi, respectively. Although all community members of the UPTC campus are willing to share their car as a second option, administrative staff feel more attracted by the public transport usage, which can be explained by their less schedule flexibility.

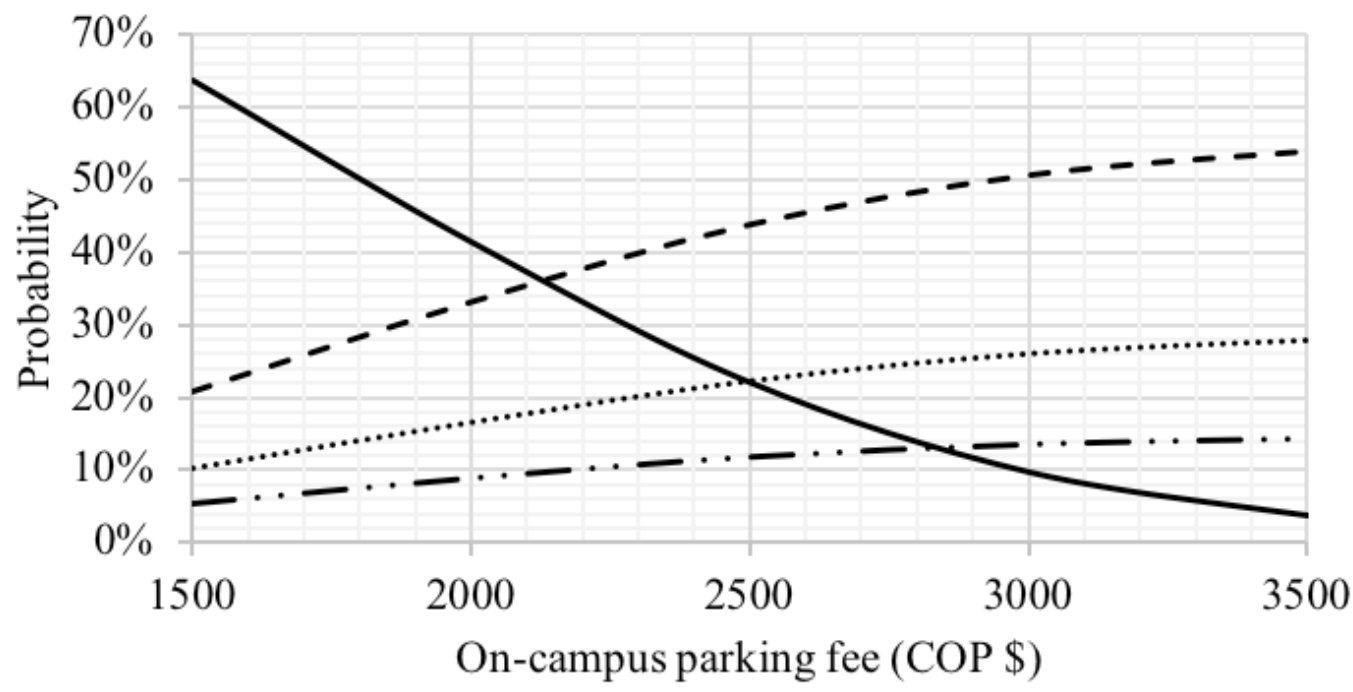

a)

Students

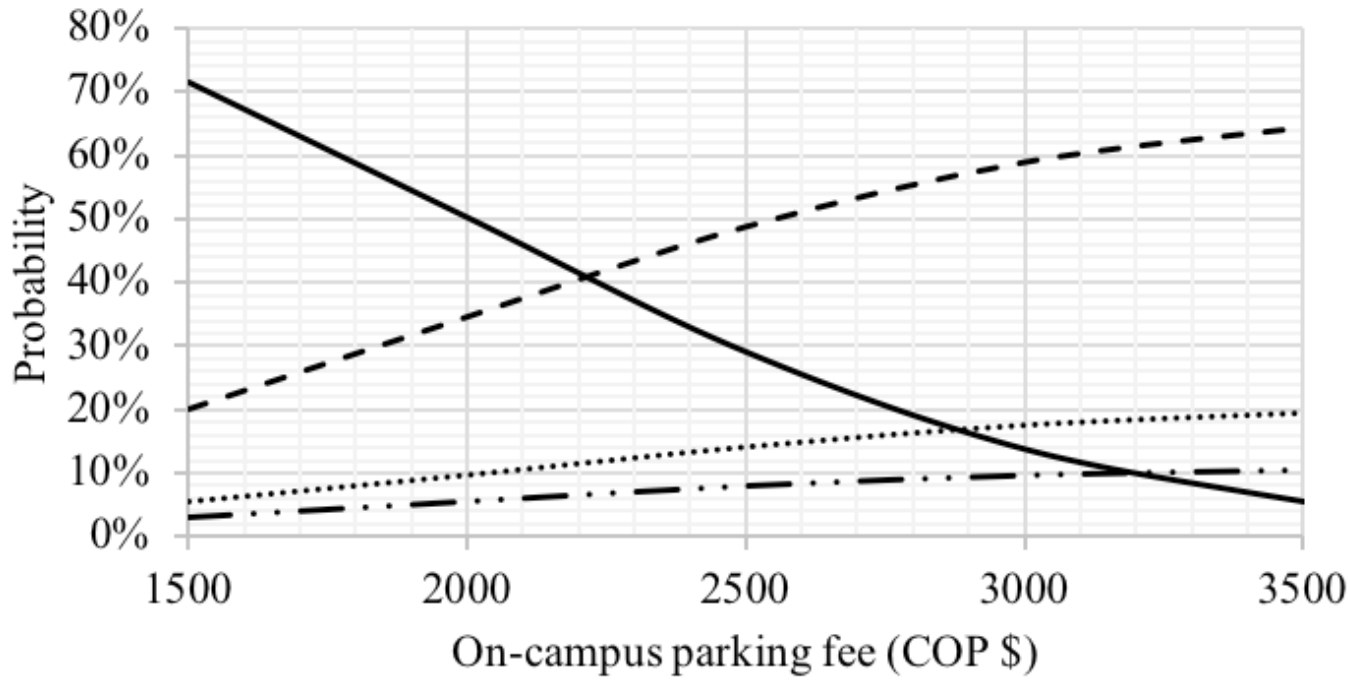

b) Teachers 


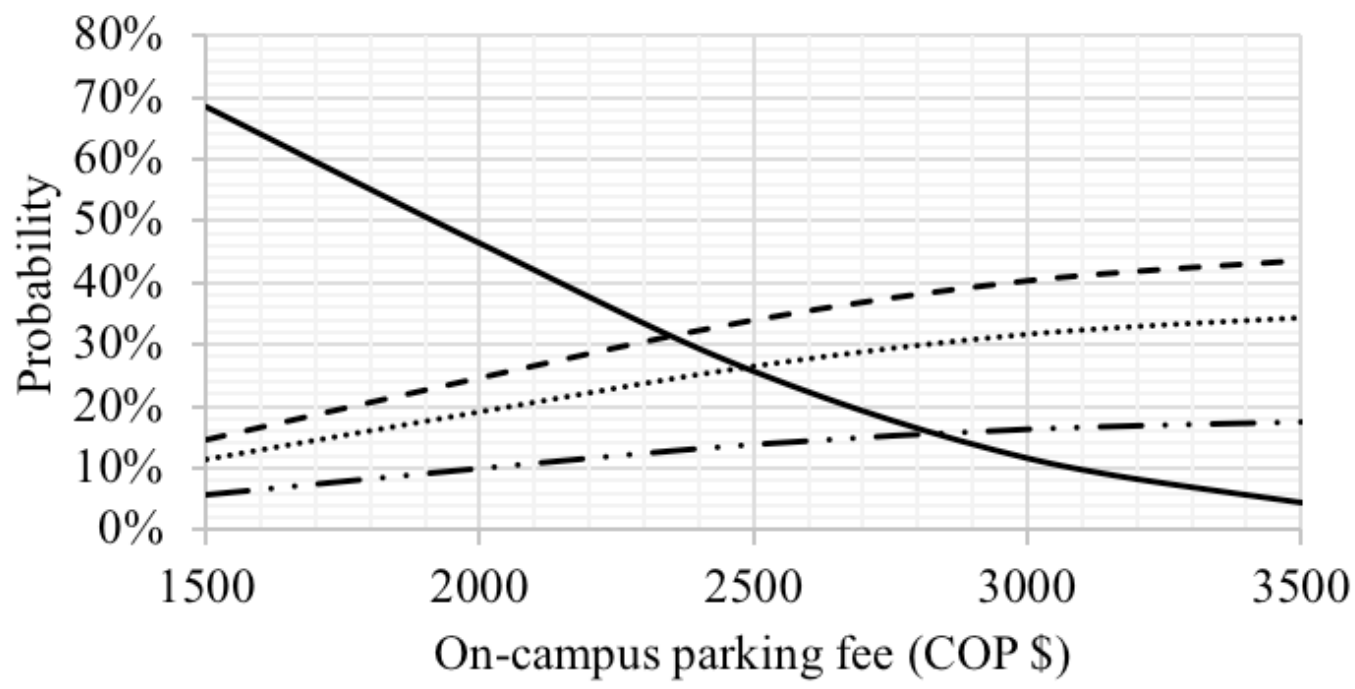

c) Administrative staff - Car - - - Carpooling - - Taxi $\cdots \cdots \cdots$.... Bus

Figure 2. Changes in market shares as a result of changes in on-campus parking fee

Additionally, our modeling results allowed us to derive the value of time savings, interpreted as the willingness to pay to save travel time. The value of time inferred from the model was $1,078 \mathrm{COP} \$ / \mathrm{min}$, i.e., 0.37 US $\$ / \mathrm{min}$. Although there are no references to the travel time valuation for car owners in the city, it is reasonable that our valuation is significantly higher than valuations made for captive users of public transport (Márquez, Pico, \& Cantillo, 2018). We considered the value of $0.37 \mathrm{US} \$ / \mathrm{min}$ is valid only in the context studied, that is, for people with cars commuting to the UPTC campus.

\section{Conclusions}

In this research, we applied an ad-hoc survey and estimated an HDC model to study the willingness of the teachers, students and administrative staff to change car use for commuting to a university campus. We demonstrated that tangible attributes have a significant effect on the mode transportation choice for commuting to university campuses, which allows for the evaluation of policies related to latent variables. Specifically, the modeling approach applied to sample data allowed us to demonstrate that, in addition to traditional tangible attributes such as waiting times, travel times, urban transportation fares and oncampus parking fees, the willingness to change car use for commuting to the campus also depends on the pro-environmental attitude and the perceived convenience of each alternative.

Given the advantages of our modeling approach, we are able to conclude that pro-environmental attitude has a positive effect on the intention to car sharing. Furthermore, having demonstrated that senior individuals and people who own a car with an above average price have weaker pro-environmental attitudes than others, allows us to better understand travelers' behavior and improve in policy formulation to encourage intentions to car sharing. As can be seen, the HDC modeling allows the modeler to form attitudinal variables in order to include them as part of the systematic utility of alternatives, providing a richer explanation of the choice process. 
Our research has two main limitations. In the first place, the fact of having applied an ad-hoc survey, designed specifically for the UPTC campus, make it necessary to adjust it before to be applied on other university campuses. The other limitation has to do with the sample size which possibly affected the statistical significance of the parameter estimates for the structural models. Regarding the stated preference experiment, the nature of the data panel provided a sufficient sample size to properly estimate the coefficients of the choice model. However, we strongly recommend increasing the sample size to improve the statistical significance of parameter estimates for the structural models.

The specific recommendations in this paper are for the UPTC main campus. However, the methodology and results from our study could be an example for other university campuses, particularly in the case of universities in developing countries, with similar characteristics to the current ones at the UPTC main campus. It is hoped that our findings will be utilized by the UPTC administration for implementing solutions that ultimately benefit sustainable mobility on the campus. We also hope that the proposed methodology and the results obtained in the Colombian context serve as a basis for future research.

Previous studies had concluded that owning a car is the main obstacle to adopting sustainable modes. However, based on the population's heterogeneity, we concluded that people who own more expensive cars are less willing to adopt sustainable transportation modes than others. This new knowledge can be useful for the accurate targeting of campaigns aimed at reducing the use of cars for commuting to the campus. For example, the UPTC administration could attempt to change the environmental attitudes focusing on people with more expensive cars.

"On-campus parking fees" is a key variable for reducing the use of cars for commuting to the campus and to finance more sustainable transportation modes, with a heightened focus on bicycle infrastructure in our case. Implementing a "carrot and stick" program to introduce parking charges only for those who do not share their cars can be a good idea, as can be concluded from modeling results. Nonetheless, this strategic line should include measures such as promoting the use of public transportation and carpooling among the university community.

Results show that imposing higher parking fees can cause a significant decrease in car market share. This induces each person to share their car as a second transportation option in order to reduce their travel costs, followed by the bus and taxi, respectively. However, members with less schedule flexibility could be more attracted to public transportation rather than carpooling, as the case of administrative staff.

Like other universities worldwide (e.g., Atherton \& Giurco, 2011), on the UPTC main campus, transportation management does not have a specific functional "owner" within the university, and therefore, we recommended the establishment of a new dependency that is responsible for managing sustainable mobility programs. Since attitudes and perceptions are significant variables in the intentions to change private car use to other transportation modes, within the framework of the education, engagement, and assessment, a first step may be to include "sustainable mobility" in the university's learning processes (Gurrutxaga et al., 2017) to create an environment in which students, teachers, and administrative staff are more willing to change their car use when commuting to the UPTC main campus. 


\section{References}

Ashok, K., Dillon, W. R., \& Yuan, S. (2002). Extending discrete choice models to incorporate attitudinal and other latent variables. Journal of Marketing Research, 39(1), 31-46. doi: 10.1509/ jmkr.39.1.31.18937

Aoun, A., Abou-Zeid, M., Kaysi, I., \& Myntti, C. (2013). Reducing parking demand and traffic congestion at the American University of Beirut. Transport Policy, 25, 52-60. doi: 10.1016/j.tranpol.2012.11.007

Atherton, A., \& Giurco, D. (2011). Campus sustainability: Climate change, transport and paper reduction. International Journal of Sustainability in Higher Education, 12(3), 269-279. doi: $10.1108 / 14676371111148054$

Azzali, S., \& Sabour, E. A. (2018). A framework for improving sustainable mobility in higher education campuses: The case study of Qatar University. Case Studies on Transport Policy. doi: 10.1016/j. cstp.2018.07.010

Barata, E., Cruz, L., \& Ferreira, J.-P. (2011). Parking at the UC campus: Problems and solutions. Cities, 28, 406-413. doi: 10.1016/j.cities.2011.04.001

Bertolini, L., \& le Clercq, F. (2003). Urban Development without more mobility by car? Lessons from Amsterdam, a multimodal urban region. Environment and Planning A: Economy and Space, 35(4), 575-590. doi: 10.1068/a3592

Bliemer, M. C. J., \& Rose, J. M. (2009a). Sample optimality in the design of stated choice experiments. European Transport Conference, Leiden, October 2009, The Netherlands.

Bliemer, M. C. J., \& Rose, J. M. (2009b). Efficiency and sample size requirements for stated choice experiments. 88th Annual TRB Meeting, Washington, DC, January 2009, USA.

Bollen, K. A. (2002). Latent variables in psychology and the social sciences. Annual Review of Psychology, 53, 605-634. doi: 10.1146/annurev.psych.53.100901.135239

Cantillo, V., \& Ortúzar, J. D. (2014). Restricting the use of cars by license plate numbers: A misguided urban transport policy. DYNA, 81(188), 75-82. doi: 10.15446/dyna.v81n188.40081

Cattaneo, M., Malighetti, P. Morlotti, C, \& Paleari, S. (2018). Students' mobility attitudes and sustainable transport mode choice. International Journal of Sustainability in Higher Education, 19(5), 942-962. doi: 10.1108/IJSHE-08-2017-0134

ChoiceMetrics. (2012). Ngene 1.1.1 User Manual \& Reference Guide. Australia. Retrieved from http:// www.choice-metrics.com/NgeneManual 120.pdf

Cruz, L., Barata, E., Ferreira, J. P., \& Freire, F. (2017). Greening transportation and parking at University of Coimbra. International Journal of Sustainability in Higher Education, 18(1), 23-38. doi: 10.1108/IJSHE-04-2015-0069

Danaf, M., Abou-Zeid, M., \& Kaysi, I. (2014). Modeling travel choices of students at a private, urban university: Insights and policy implications. Case Studies on Transport Policy, 2(3), 142-152. doi: 10.1016/j.cstp.2014.08.006

dell'Olio, L., Cordera, R., Ibeas, A., Barreda, R., Alonso, B., \& Moura, J. L. (2018). A methodology based on parking policy to promote sustainable mobility in college campuses. Transport Policy. doi: 10.1016/j.tranpol.2018.03.012

Dogterom, N., Bao, Y., Xu, M., \& Ettema, D. (2018). Willingness to change car use under a tradable driving credits scheme: A comparison between Beijing and the Netherlands. Journal of Transport and Land Use, 11(1), 499-518. doi: 10.5198/jtlu.2018.1039

Doornik, J. A. (2015). Object-oriented matrix programming using ox. (3rd ed.). London: Timberlake Consultants Press and Oxford. Retrieved from www.doorn ik.com 
Filipovitch, A., \& Boamah, E. F. (2016). A systems model for achieving optimum parking efficiency on campus: The case of Minnesota State University. Transport Policy, 45, 86-98. doi: 10.1016/j. tranpol.2015.09.010

Finlay, J., \& Massey, J. (2012). Eco-campus: Applying the ecocity model to develop green university and college campuses. International Journal of Sustainability in Higher Education, 13(2),150-165. doi: $10.1108 / 14676371211211836$

Gurrutxaga, I., Iturrate, M., Oses, U., \& Garcia, H. (2017). Analysis of the modal choice of transport at the case of university: Case of University of the Basque Country of San Sebastian. Transportation Research Part A, 105, 233-244. doi: 10.1016/j.tra.2017.04.003

Hancock, L., \& Nuttman, S. (2014). Engaging higher education institutions in the challenge of sustainability: Sustainable transport as a catalyst for action. Journal of Cleaner Production, 62, 62-71. doi: 10.1016/j.jclepro.2013.07.062

Hook, W. (2007). Reducing transport-related greenhouse gas emissions in developing countries: The role of the global environmental facility. In D. Sperling \& J. S. Cannon (Eds.), Driving climate change (pp. 165-188). Cambridge, MA: Academic Press. doi: 10.1016/B978-012369495-9/50011-7

Kaplan, D. H. (2015). Transportation sustainability on a university campus. International Journal of Sustainability in Higher Education, 16(2),173-186. doi: 10.1108/IJSHE-03-2013-0023

Khattak, A., Wang, X. Son, S., \& Agnello, P. (2011). Travel by university students in Virginia: Is this travel different from travel by the general population? Transportation Research Record: Journal of the Transportation Research Board, 2255(1), 137-145. doi: 10.3141/2255-15

Levy, B. L. M., \& Marans, R. W. (2012). Towards a campus culture of environmental sustainability: Recommendations for a large university. International Journal of Sustainability in Higher Education, 13(4), 365-377. doi: 10.1108/14676371211262317

Manville, M., \& Shoup, D. (2005). Parking, people, and cities. Journal of Urban Planning and Development, 131(4), 233-245. doi: 10.1061/(ASCE)0733-9488(2005)131:4(233)

Márquez, L., Cantillo, V., \& Arellana, J. (2018). Assessing the influence of indicators' complexity on hybrid discrete choice model estimates. Transportation, 2018, 1-24. doi: 10.1007/s11116-018-9891-6

Márquez, L., Pico, R., \& Cantillo, V. (2018). Understanding captive user behavior in the competition between BRT and motorcycle taxis. Transport Policy, 61, 1-9. doi: 10.1016/j.tranpol.2017.10.003

Miralles-Guasch, C., \& Domene, E. (2010). Sustainable transport challenges in a suburban university: The case of the Autonomous University of Barcelona. Transport Policy, 17, 454-463. doi: 10.1016/j. tranpol.2010.04.012

Ng, W.-S. (2017). Work schedule flexibility and parking preferences. Journal of Transport and Land Use, 10(1), 57-75. doi: 10.5198/jtlu.2016.554

Ortuzar, J. D., \& Willumsen, L. G. (2011). Modelling transport. Hoboken, NJ: Wiley

Pitsiava-Latinopoulou, M., Basbas, S., \& Gavanas, N. (2013). Implementation of alternative transport networks in university campuses: The case of the Aristotle University of Thessaloniki, Greece. International Journal of Sustainability in Higher Education, 14(3), 310323. doi: 10.1108/ IJSHE-12-2011-0084

Riggs, W. (2014). Dealing with parking issues on an urban campus: The case of UC Berkeley. Case Studies on Transport Policy, 2, 168-176. doi: 10.1016/j.cstp.2014.07.009

Soria-Lara, J. A., Marquet, O., \& Miralles-Guash, C. (2017). The influence of location, socioeconomics, and behavior on travel-demand by car in metropolitan university campuses. Transportation Research Part D, 53, 149-160. doi: 10.1016/j.trd.2017.04.008

Soto, J. J., Márquez, L., \& Macea, L. F. (2018). Accounting for attitudes on parking choice: An integrated choice and latent variable approach. Transportation Research Part A, 111, 65-77. doi: 10.1016/j. tra.2018.03.003 
Stein, P. P., \& Rodrigues, A. N. (2017). Barriers, motivators and strategies for sustainable mobility at the USP campus in São Carlos, Brazil. Case Studies on Transport Policy, 6(3), 329-335. doi: 10.1016/j. cstp.2017.11.007

Szolnoki, G., \& Hoffmann, D. (2013). Online, face-to-face and telephone surveys-Comparing different sampling methods in wine consumer research. Wine Economics and Policy, 2(2), 57-66. doi: 10.1016/j.wep.2013.10.001

Terrier, P., Berdier, C., \& Bouyer, M. (2017). La mobilité sur le campus Lyon Tech-la-Doua: Approche systémique et scénarios en éco-mobilité. Développement Durable et Territoires, 8(1), 1-22. doi: 10.4000/developpementdurable.11622

Vale, D. S., Pereira, M., \& Viana, C. M. (2018). Different destination, different commuting pattern? Analyzing the influence of the campus location on commuting. Journal of Transport and Land Use, 11(1), 1-18. doi: 10.5198/jtlu.2018.1048

Vásquez, L., Iriarte, A., Almeida, M., \& Villalobos, P. (2015). Evaluation of greenhouse gas emissions and proposals for their reduction at a university campus in Chile. Journal of Cleaner Production, 108, 924-930. doi: 10.1016/j.jclepro.2015.06.073

White, S. S. (2003). Sustainable campuses and campus planning: Experiences from a classroom case study at the University of Kansas. International Journal of Sustainability in Higher Education, 4(4), 344-356. doi: 10.1108/14676370310497561 